\section{La ilustración en la industria discográfica norteamericana de los años cincuenta}

Illustration in the North American Record Industry in the 50's
1. El origen de la música ilustrada: Alex Steinweiss y la pionera Columbia

En un mundo donde la comunicación artística y los estímulos visuales nos invaden, nos resulta prácticamente imposible pensar en un producto tan masivo como puede ser la música vacío de contenido gráfico. Una conjunción entre sonido e imagen que asumimos ligada entre sí, capaz de condicionarnos como consumidores, así como capaz de generar un desarrollo estético que hemos ido comprobando a lo largo de la historia de la imagen aplicada al disco.

Comenzaremos pues, remontándonos al inicio de aquellas propuestas artísticas que fueron desarrolladas a través de la ilustración tratando de contextualizar su origen, con el objeto de analizar los aspectos más relevantes de su desarrollo.

Encontramos el nacimiento de tales propuestas en la discográfica Columbia Records, la cual se remonta a la década de 1880; tratándose del sello discográfico más longevo y en vigencia. Una compañía que resultó ser pionera en muchos avances relacionados con la elaboración de sus grabaciones, siéndolo también en el campo del diseño gráfico, ya que fue allí donde surgieron las primeras portadas de discos ilustradas; una auténtica revolución que supuso una nueva forma de ver, vender y entender la música. Lo cual nos lleva a plantearnos cuáles fueron los objetivos o impulsos que llevarían a idear el giro estético del producto, así como sus posteriores características y repercusiones.

El culpable de tal acontecimiento fue un joven llamado Alex Steinweis. De padre polaco y madre letona, Steinweis se crió en Brooklyn (Nueva York). Una vez graduado ingresó en Parson School of Design, donde comenzó a interesarse por el Modernismo y las Vanguardias Europeas, así mismo conocería al cartelista alemán Lucian Bernhard y al vienés Joseph Binder; influencias clave que, tal y como veremos más adelante, marcarían las pautas visuales de aquellos primeros covers ilustrados.

Tras haber realizado algunos encargos gráficos y tras su paso por el ejército durante la Segunda Guerra Mundial, donde estuvo realizando cartelería y propaganda militar, le llegó la noticia de que Columbia Records precisaba un director de arte; siendo finalmente contratado por William Paley, el fundador de la discográfica.

Cabe mencionar que Columbia no pasaba por su mejor momento económico y parte de la plantilla se mantenía reticente debido a la cor ta edad y experiencia de Steinweiss, de 22 años. Sin embargo Paley vislumbró algo que le provocó un interés especial por el joven, a quien convirtió en el primer director de arte de Columbia, en el año 1939

Una decisión basada en una completa confianza depositada en el joven artista, fruto tal vez de aquella actitud empresarial que comenzaba a valorar el aporte estético como vía para la comercialización de un producto.

Alex, el único empleado que se dedicaba con exclusividad a campañas publicitarias, contó con un despacho propio, con mesa de dibujo, un aerógrafo y materiales básicos.
Palabras clave: llustración ca, 40's.

Key words: Illustration Record, Design, Northamerica, 40's. \section{to some new stylistic forms and to a wide iconography generated for the most part by the work of the artist. In conclusion, we could consider this} period as the starting point for the illustration of covers, with outstanding names like Alex Steinweiss, Jim Flora or David Stone Martin heading a long list of artists whose mission was based on illustrating Swing, Jazz an those new ways of making music that stirred up Northamerican's culture from the old New Orleans. 
Su trabajo inicial se basó en la creación de carteles, catálogos y reclamos publicitarios; labores que el joven realizaba con la implicación y el empeño que le caracterizaban. No obstante, existía un asunto descuidado que Steinweiss consideraba de vital importancia: las cubiertas de los discos.

"La forma en la que se vendían aquellos álbumes era ridícula. Las cubiertas eran simplemente de color marrón, beige o verde. Pensé iquién demonios va a comprar esta cosa? Nada te empuia a ello, no tiene atractivo [ . ] Así que les dije que me gustaría comenzar a diseñar covers"'?

Comprobamos como en efecto tal objeto suplía sus necesidades funcionales, quedando las de carácter estético en un segundo plano. Así mismo, tal y como ha ocurrido a lo largo de la historia del diseño gráfico y la ilustración aplicada a producto con fines comerciales, el creador en cuestión debía valorar las necesidades del usuario; unas necesidades en este caso estéticas que debían quedar resueltas con la finalidad de dar lugar a un objeto cuidado y en consecuencia incentivar un mayor consumo del mismo.

Pasando a analizar las características formales del producto, cabe señalar que por aquel entonces los discos se comercializaban envueltos en fundas de cartón o papel estraza, agujereadas en el centro para mostrar la etiqueta con el nombre del artista estampado. En suma, su breve duración (5 minutos de música por cara) hizo que los álbumes a menudo se pusieran en venta de tres en tres o de cuatro en cuatro, unidos en esta ocasión por un lomo de cartón. Un envoltorio austero y rudo, cuya vigencia Steinweiss no podía comprender

"Consideraba que aquello no era manera de envolver algo tan hermoso como la música. Me imaginaba carteles a color que combinasen con el espiritu de cada disco en lugar de aquellas bolsas-lápida de papel o cartón".2

Fue entonces cuando propuso reemplazar tal envoltorio por una imagen atractiva, algo con lo que ubicar la gráfica a la altura de la pieza musical contenida, con el objetivo de seducir al comprador, generando un cambio estético que sirviera de premisa a la pieza musical.

Pasando a continuación a analizar el desarrollo de tal idea, cabe remontarnos al año 1940, cuando Alex Steinweiss decidió diseñar portada del disco Smash Song Hits de Richard Rodgers y la Imperial Orchestra, el cual rodaba a 78rpm.

Para llevar a cabo tal proyecto, contó con la ayuda de un fotógrafo de la discográfica, con quien se desplazó al Teatro Imperial de Nueva York, logrando que el director cambiase durante unas horas las letras de la marquesina, donde se escribió el título del disco, el nombre del artista y la compañía.

A partir de las fotografías tomadas, Steinweiss trabajó gráficamente la 1 STEVEN HELLER. "Reputations: Alex Steinweiss", Eye Magazine no 76 vol. 19. 2 STEVEN HELLR, "Reputations: Alex Steinweiss", Eye Magazine no. 76 vol. 19 imagen, logrando una composición con la que rompió todos los moldes estereotipos anteriores; un fotomontaje sobre fondo negro rodeado por una insinuación de disco a base de círculos concéntricos rojos.

El diseño supuso toda una revolución social, no únicamente por su carácter innovador, si no además por tratarse de la primera portada de disco ilustrada; lo cual causó un revuelo que se vio reflejado en el disparo de las ventas, superadas en un $800 \%$.

Tal acontecimiento, nos hace pensar en la capacidad convincente de la imagen, la valoración de tal incentivo adherido al producto y su capacidad de atracción, con su consecuente impulso consumista.

Un suplemento estético que había resultado ser valorado por una sociedad que estaba cambiando; una sociedad que valoraba el grado de exclusividad y modernidad que era capaz de aportar la imagen ilustrada.

Comprobamos pues como lo que Stenweiss había ideado fue el comienzo de una nueva forma de arte y una nueva forma de vende discos que cambió para siempre el rumbo de la industria musical generando un infinito de posibilidades gráficas que enriquecerían la identidad de tal producto.

Una nueva forma de comunicación visual con unas pautas propias que tal y como iremos analizando con posterioridad, irían generando una progresiva iconografía; dando lugar a una identidad común, presente incluso en la metodología empleada y las técnicas y procesos gráficos de desarrollo.

Fue desde ese instante cuando las portadas ilustradas comenzaron a sustituir aquellos viejos sobres, y la revolución de los álbumes ilustrados pronto se extendería por otros sellos norteamericanos.

Alex Steinweiss continuó elaborando diseños para Columbia Records durante los años cuarenta y logró hacer historia de nuevo en 1948, cuando el vinilo sustituyó a la laca y se estandarizó el formato de os discos de 33 revoluciones por minuto.

Se dice que Steinweiss fue el primero en llamar al soporte Long Play (LP, larga duración), así como el pionero en diseñar un packaging específico para el producto, basado en una cubierta elaborada con cartón fino impreso, lo que comúnmente conocemos como disco de vinilo y que pronto se convertiría en el estándar de la industria.

Un envoltorio innovador que resultaba imprescindible para una forma de arte innovadora. Y es que, el desarrollo gráfico de tales diseños, precisaba un soporte específico, que respondiera a sus nuevas características formales y morales; resultantes de la idea de lograr una conjunción equitativa entre la música y el arte gráfico. Un arte que, tal y como podemos comprobar a través del trabajo de Steinweiss, quien desarrolló su estilo a base de trazos estilizados y juegos tipográficos, iba respondiendo a unas características que nos hacen pensar en la cartelería europea de los años treinta, con recursos de artistas como Cassandre, Jean Carlo y Paul Colin, o las influencias propias del Art Deco.

Una serie de similitudes que en el caso de Steinweiss, podemos vislumbrar en la utilización de colores puros generando saturados contrastes en composiciones donde combinar la geometría de la esfera y el cubo con la ilustración manual. Un dinamismo logrado a base de cromados con aerógrafo y juegos de curvas y diagonales, que irian evolucionando hasta unas propuestas cada vez más sintéticas y cercanas a la abstracción, con evidentes influencias de artistas como Kandinsky, Mondrian o Paul Klee. 
Debemos tener en cuenta que el arte abstracto comenzaba a convertirse en una tendencia a la orden del día, progresivamente valorada por la sociedad y vinculada a la modernidad y al sentido de la libre expresión; una vía gráfica que encajaba a la perfección con la representación de una forma de arte tan sensorial como lo es la música.

Continuando con el análisis de la evolución de tal producto, es preciso hacer mención de otra figura clave en el desarrollo estético de aquellos primeros discos lanzados por Columbia: el polifacético Neil Fujita. Un artista vanguardista de descendencia japonesa que fue contratado por la compañía en el año 1948, con el objetivo de formar un departamento de diseño y continuar con el desarrollo del legado de Steinweiss. La consolidación del tal departamento resultaba imprescindible para hacer frente a las innovadoras propuestas que estaba comercializando Blue Note, una discográfica especializada en el Jazz, que con el talento del fotógrafo Francis Wolff y algunos diseñadores como Paul Bacon o Reid Miles había apostado por un estilo gráfico vanguardista y atrevido mediante la utilización de otros procesos artísticos como la fotografía, que daría lugar a la histórica disputa existente entre la imagen ilustrada y la fotográfica. Una vinculación debatida, que también agitaría la industria del disco, tal y como desarrollaremos con posterioridad; y que, en suma, generaría entre ambas discográficas una competencia de tipo comercial.

Neil Fujita supo convertir los discos en auténticas obras de arte contemporáneo." Una síntesis de los principios de la Bauhaus y la sensibilidad japonesa", proclamaría el diseñador Milton Glaser.

Y es que Fujita, quería lograr que la cubierta del disco contara la música que el objeto ocultaba en su interior, ya que entendía el Jazz como una forma de abstracción que expresaba a través de pinturas surrealistas a base de colores vibrantes y formas geométricas, influenciadas por el arte de Vanguardia de emblemáticos artistas como Pablo Picasso George Braque, Joan Miró o Paul Klee; lo cual dio lugar al desarrollo de auténticas obras maestras en el ámbito gráfico de la industria musical, tales como el Time Out de Dave Brubeck o Ah Um de Charles Mingus.

Neil Fujita, convertido en director de arte a mediados de los años cincuenta, también trabajó el diseño a través de juegos tipográficos y tintas planas, así como el fotomontaje; de nuevo recursos tomados de la escuela de la Bauhaus. Un ejemplo de ello sería la emblemática portada que realizó para The Jazz Messengers; una deconstrucción de formas con las que fundir la geometría irregular con fotografías en blanco y negro, aportando dinamismo y frescura, a través de la utilización del color naranja.

Comprobamos pues cómo progresivamente evolucionaría la

funcionalidad de tal producto, otorgándole un doble valor en forma de reclamo artístico

$Y$ es que el consumidor ya no compraba únicamente un producto meramente musical, sino que contaba con el incentivo de poder gozar de una pieza artística en forma de ilustración o incluso pintura, esta vez aplicadas a un nuevo formato. Una nueva democratización de la obra artística, tal y como había ocurrido con la cartelería, que en suma era contenedora de una grabación musical.

Además de desarrollar su particular estilo, Neil Fujita trató de nutrir la personalidad gráfica de Columbia contando con diseñadores y fotógrafos independientes, tales como William Claxton, Burt Goldblatt, Richard Avedon, Ben Shahn o Tom Allen; logrando desarrollar propuestas atrevidas y generar tendencia en este universo del cover ilustrado que tan velozmente se extendía por las compañías discográficas.

Una nueva vía de creación que supuso el punto de encuentro de artistas plásticos de diversos ámbitos de desarrollo, que encontrarían en la portada de disco un nuevo formato para la expresión gráfica y una nueva posibilidad comunicativa, en un soporte específico para el producto.

Como podemos comprobar, el perfil de aquellos diseñadores

gráficos, resultaba ser de carácter multidisciplinar, ya que combinaban recursos de diversas áreas de la expresión artística; lo cual podríamos entender como una premisa favorable que daría lugar a tal amplitud de planteamientos y recursos estéticos.

Entre los artistas que pasaron por la pionera Columbia, cabe hacer especial mención de los diseños propuestos por Ben Shahn, quien fue considerado un avanzado a su tiempo y una influencia para artistas que dedicarían su carrera a la ilustración.

Una personalidad desbordante que resaltó por su arte reivindicativo y su vinculación a la temática social, a través de un estilo puro de trazo expresionista, que supo encajar a la perfección en las cubiertas de discos, pese a no tratarse de su mayor área de desarrollo.

Podemos pues comprobar cómo el producto, tal y como ocurre en la actualidad, no contaba con límites conceptuales; cabiendo la posibilidad de introducir contenidos de un modo más o menos directo, en los que reivindicar o sacar a la luz problemática de carácter social, aprovechando tal medio como un nuevo formato de transmisión de información o crítica.

Por otra parte, de nuevo encontrando especial expresividad en sus creaciones, resulta igualmente curioso el trabajo realizado por Tom Allen, un ilustrador formado en el Instituto de Arte de Chicago, que se diferenció por su personal visión del Jazz, el Country y el Western, y su afición por los retratos de músicos y sorprendentes recursos gráficos a partir de una limitada paleta de color y un gesto pictórico; un artista con quien Neil Fujita tuvo especial trato y admiración, y a quien recurrió para cuantiosos encargos de Jazz.

En definitiva, fueron numerosos los artistas que enriquecieron la imagen de Columbia Records desde aquella reveladora idea de Alex Steinweiss; artistas que supieron entender las necesidades del consumidor, poniendo su talento a disposición de la cubierta del disco y entre los que con posterioridad también encontraríamos a grandes como Milton Glaser y sus sinuosas siluetas de músicos generadas con tintas planas; o Saul Bass, cuya personalidad incomparable marcó a base de rotundidad compositiva y colores sólidos la gráfica de las bandas sonoras del cine negro. 


\section{La libertad creativa y el universo delirante de Jim Flora}

La invención e incorporación en el mercado de aquel nuevo formato comunicativo a disposición de ilustradores y artistas plásticos, nos conduce a plantearnos una búsqueda de características que fueran definiendo u homogeneizando de forma progresiva el amplio abanico de posibilidades consecuentes de la novedad artística que supuso la invención del disco ilustrado.

Un origen que estuvo marcado, tal y como hemos señalado con anterioridad, por la existencia de un cúmulo de artistas, con influencias bien cercanas a las Vanguardias europeas y los principios de la Bauhaus, pero sin puntos delimitantes que nos lleven a pensar en un estilo común y definitivo.

Pasaré pues a analizar a continuación tal libertad creativa, a través de la figura cuya personalidad gráfica resulto más innovadora y extrema: el inconfundible Jim Flora.

Con el objetivo de acercarnos al estudio de su arte y la consecuente extracción de conclusiones relacionadas con la libertad común a otros ilustradores. Considero relevante comenzar con una breve contextualización del artista, la cual nos dará algunas de las pistas claves para el desarrollo de su personalidad estilística.

Jim Flora, nacido en Ohio en 1914, fue becado durante su juventud para estudiar arquitectura en la Boston Architectural League; un traslado a una gran ciudad donde poder multiplicar sus estímulos culturales y su aprendizaje gráfico, a base de galerías y bibliotecas que supondrían para el joven una aproximación al arte de grandes maestros e influyentes piezas fundamentales en el desarrollo de su trabajo como Paul Klee, Joan Miró, Pablo Picasso, Carlos Mérida o Alexander Calder, descubriendo a su vez la magia del arte precolombino primitivo y la maestría de algunos de los más reconocidos artistas murales mexicanos, tales como José Clemente Orozco o Diego Rivera.

Comprobamos de inicio, una amplitud en las fuentes referenciales del artista, quien incorporó a las Vanguardias europeas el arte mural y primitivo que bien resultarían convertirse en influencias directas de su posterior estilo.

La Gran Depresión y sus consecuentes dificultades económicas y laborales, le obligarían a abandonar los estudios de arquitectura, dando un giro a su vida que le llevó a estudiar arte en la Art Academy tras su regreso a Cincinnati; donde conoció al muralista y profesor de composición Karl Zimmerman, con quien realizó sus primeros murales comerciales, así como a su mano derecha Robert Lowry, con quien creó la revista Little Man Press, una publicación literaria en la cual Flora comenzaría a desarrollar su ingenio, tallando tipografías en madera y explotando la inconfundible gracia tan propia de sus ilustraciones.

Años después, convencido de que su trabajo encajaría en Columbia Records y sería capaz de dar un soplo de aire fresco e innovación a las carátulas de discos, envió su portfolio a uno de los responsables de Columbia en Nueva York: el reconocido Alex Steinweiss.

Jim Flora pronto comenzó a trabajar en la discográfica, corría el año 1942, y era el momento de sumar su caótico estilo al diseño de portadas atreverse con nuevas propuestas arriesgadas de ilustración con el fin de seguir aumentando las ventas y el atractivo de aquel producto.

Al contrario que Steinweiss, gran aficionado a la música clásica, cabe señalar que Jim Flora sentía una atracción especial por aquellos frenéticos ritmos de Jazz que estaban sacudiendo la cultura norteamericana, lo cual otorgaba una gran convicción a sus propuestas creativas.

Era un gran coleccionista y amante del Jazz y el Swing , admirador de grandes como Louis Armstrong o Benny Goodman.

"El jazz para mí..." admitió Flora "si no hay diversión, no quiero oírlo...supongo que lo llevo en el alma. Amo la improvisacion del jazz y amo sinceramente a la gente que domina sus instrumentos y es capaz de hacer lo que quiera con ellos"3

Una espontaneidad que veríamos reflejada en cada una de sus creaciones y cada uno de sus trazos derrochantes de frescura; lo cual lleva a cuestionarnos el grado de influencia que pudieron tener tan revolucionarios géneros musicales en el modo de creación de la obra, tanto técnica como formalmente, o referente al contenido.

Debemos comprender que tales artistas se encontraban en una situación novedosa de admiración y éxtasis al escuchar tales piezas musicales y al enfrentarse a aquellos encargos sin fronteras; lo cual tal vez fuera una de las causas por las cuales Flora desarrollaría durante su paso por Columbia una labor creativa que lo convertiría en uno de los máximos referentes de la historia de la llustración, gozando de una libertad creativa prácticamente absoluta.

"La gente de hoy en dia no podria hacer lo que hicimos entonces. Hay mucho cuento a propósito de las portadas de discos y de cómo deberían hacerse. Todo el mundo opina. En aquella época, casi todo lo que hacíamos era aceptado"4

Una confianza plena que vemos reflejada en la continua ruptura de estereotipos; permitiendo incluso la omisión de informaciones relevantes como el nombre del músico o el propio título del disco.

Transgresiones tan arriesgadas como reveladoras, que ya desde su origen fueron capaces de ir abriendo caminos de creatividad en el ámbito del diseño gráfico aplicado al disco.

Resulta sorprendente comprobar cómo la única premisa por la que los artistas se regían era la ilustración, la gráfica. Únicamente importaba la imagen, la expresión artística, la belleza de tal objeto; la cual debía reflejar esa explosión de ritmos salvajes y toda la diversión y emociones que era capaz de trasmitir la música.

Una libertad que, podemos afirmar, se convirtió en uno de los puntos característicos de un nuevo arte en proceso de construcción, con un desarrollo de popularidad que resultó abrumador, y cuya velocidad de expansión aún no había encontrado el momento de contemplar ningún tipo de normas o estereotipos afianzados.

Se trataba de un arte aplicado que resultaba completamente nuevo 3 Interview with Jim Flora, Irwin Chusid. Rowayton, CT, 1998 .
4The unedited 1990 interview, Angelynn Grant. 1990. en una industria que prefirió otorgarle toda responsabilidad estética a los diseñadores y artistas graficos, volcando en ellos, tal y como 
hemos señalado con anterioridad, una confianza casi plena que dejaría el empaquetado de la música en manos del arte plástico.

Pasando a continuación a centrarnos en las características formales de tan relevante ilustrador, cabe señalar que encontramos en Flora una iconografía a base de caos y rupturas de las leyes de la física, la espacialidad y el orden, rompiendo con todo convencionalismo a base de horror vacui personajes estrafalarios, deformaciones casi post-cubistas, instrumentos imposibles, formas geométricas, dinamismo, tensión y sarcasmo.

Unas ilustraciones tan escalofriantes como absurdas, tan cálidas

como diabólicas, e incluso eróticas. Una fiesta de colores, con abusos de piernas y brazos, o ausencias de ojos, creando seres y composiciones extravagantes, que podríamos considerar como punto de partida de una sociedad que estaba desarrollando nuevas formas de música que requerían su especial representación gráfica.

Tratando pues de comprender la influencia que el Jazz tuvo en el desarrollo de éste tipo de propuestas, podemos vislumbrar de qué modo tal género quedaba marcado por la innovadora ruptura de leyes, incesantes cambios rítmicos, espontaneidad e improvisación.

Un música en la cual numerosos artistas encontrarían su fuente de inspiración y la versión sonora de su personal iconografía.

Así vemos como Jim Flora encontró en Columbia un lugar donde amar el Jazz, permitiéndole expresar su universo creativo y liberar sus ideas a base de trazos y colores, además de asistir a algunas sesiones de grabación y recibir discos de sus admirados músicos antes incluso de que salieran a la venta.

Flora fue ascendiendo en la compañía, y tras el abandono de Steinweiss tomó su cargo, aumentando responsabilidades como posterior gerente de publicidad y gerente de promoción y ventas; unas responsabilidades que fueron sustituyendo el tiempo de creación por el de gestión de estrategias empresariales, lo cual le llevaría a abandonar Columbia Records y trasladarse a México con su familia.

A su regreso a Estados Unidos, la industria discográfica había sufrido muchos cambios; una repentina expansión de ritmos juveniles que alborotaban las masas a base de un nuevo sonido fresco y popular que se hacía llamar Rock\&Roll.

Tal fenómeno irrumpió también en el diseño gráfico y perjudicó especialmente a la ilustración; la cual fue sustituyéndose por la fotografía y los demandados retratos de ídolos adolescentes.

Comprobamos una vez más, de qué modo el desarrollo de la sociedad había sido el responsable de los cambios en el territorio artístico, suponiendo una necesaria variación de criterios estéticos y reclamos publicitarios.

El arte gráfico a disposición del consumidor llevaría al artista comercial a replantear su ámbito creativo y la libertad a él adherida.

En el caso de Flora, no abandonó el mundo discográfico y continuó realizando algunos diseños cuando Bob Jones, director de arte del sello RCA Victor, decidió contar con él, de nuevo como ilustrador de covers.
Pese al éxito abanderado por Elvis Presley, considerado como absoluto icono del Rock\&Roll, Jim Flora supo adaptarse a las nuevas necesidades estéticas, mantenerse al margen de tal boom y continuar su trayecto profesional, dando lugar a algunos de sus más relevantes trabajos, como el Mambo for cats, las portadas realizadas para Charlie Barnet y Benny Goodman, The panic is on de Nick Travis Quintet o Courts the count de Shorty Rogers.

Jim Flora fue pues una prolífica figura clave en el desarrollo de la lustración aplicada al diseño gráfico, un embriagante talento que podríamos considerar como la perfecta representación de aquella libertad creativa que invadió las industria discográfica a principios de los años cincuenta; la cual a pesar de la llegada del Rock\&Roll y la progresiva popularidad de la fotografía, supo mantener el formato del disco ilustrado, logrando algunos de los más creativos e influyentes trabajos.

Unas obras en las cuales la efervescencia de la música Jazz sirvió de precedente para su desarrollo estético; siendo además el objetivo primordial de la mayor parte de ilustradores, la ardua tarea de lograr transmitir a través de una única imagen, las cualidades sensitivas que eran capaces de explotar aquellos pentagramas musicales.

Unos ritmos acelerados que bien conjugaban con la fuerza estilística de Jim Flora, quien odiaba lo "estático" y tal y como expresó en alguna ocasión, lo único que quería era "crear un pedacito de emoción" 5 .

\section{Legado y técnica de David Stone Martin}

Continuando con el análisis de la variedad gráfica que tuvo cabida en la creación de tales álbumes ilustrados, cabe resaltar con convicción el legado del ilustrador David Stone Martin, a quien podríamos considerar como uno de los máximos exponentes del cover ilustrado.

Un artista que tanto conceptual como técnicamente contó con un estilo muy propio que en ámbito discográfico se ha convertido en la definición de la atmósfera de los años cincuenta.

Nacido en Chicago, cuna del Blues y la creación musical, David Stone Martin se graduó en la escuela de arte, trasladándose posteriormente a Nueva York, donde comenzaría a desarrollarse como artista plástico. Una personalidad bien vinculada al Jazz que le llevo a relacionarse con numerosos músicos que seducidos por su arte le encargaron de primera mano la ilustración de sus álbumes, como el caso del pianista Mary Lou Williams para quien realizó su primer diseño.

Dentro de su prolífica carrera, es preciso hacer mención de su paso por las discográficas Granz, Norgran y Cleff, ya que se tratan de los sellos en los que realizó sus más reconocidos y valorados trabajos. Unas propuestas que nos conducen a hacer balance al respecto de un estilo que logró convertirse en el más representativo de la música Jazz, a través de una gráfica con predilección por el retrato, y la cual reconoció estar influenciada por la línea expresiva de Ben Shahn; donde sin embargo optó por otorgar una mayor sensibilidad con una sutileza metodológica que bien definía los aspectos propios de tal género musical. 
El ilustrador, quien diseñó más de 400 discos, se ha convertido pues en un clásico esencial de la música ilustrada, cuyas propuestas navegan por el expresionismo, lograda a través de una transgresión, a base de contrastes y rotundidad colorista, generada a menudo a partir de una limita paleta de color, con frecuencia limitada a una única gama. Una técnica de líneas líquidas que fluyen derrochando elegancia y frescura a base de un trazo de pincel con recursos vanguardistas y rupturas compositivas, integradas con una tipografía de carácter manual.

Una clásico cuya sensibilidad y estilizada estética supondría una

auténtica revolución estilística en la gráfica del álbum ilustrado.

\section{Blue Note Records: identidad de jazz}

Paralelamente al desarrollo de la ilustración en la Industria de disco, fueron surgiendo otras propuestas artísticas que igualmente revolucionarían la plástica del producto, tales como la utilización de la fotografía o la aplicación de juegos tipográficos con un mayor grado de racionalidad.

Unos diseños sofisticados y vanguardistas que encontraron su foco de desarrollo en la discográfica Blue Note, fundada en 1939 por Alfred Lion, y considerada una de las compañías más aventajadas e innovadoras en el ámbito del diseño gráfico, así como una discográfica especializada en aquel género efervescente que dio un giro a la sociedad norteamericana: el Jazz.

Nos cuestionamos pues, de qué modo se comportaría la fotografía en tal producto, siendo conscientes de unos evidentes cambios metodológicos y expresivos que enriquecerían y en ocasiones se complementarían con las anteriores portadas ilustradas. Un repaso por los principales artistas que pasaron por esta transgresora discográfica con el objeto de descifrar los componentes característicos de sus propuestas graficas, con un mayor valor otorgado al orden y al minimalismo.

Cabe comenzar resaltando el trabajo de Francis Wolff, posiblemen-

te el máximo exponente de la fotografía jazzística.

De carácter Vanguardista, el alemán Wolff se caracterizó por sus rotundas fotografías con las que supo retratar la cotidianidad de los músicos de Blue Note; mostrando su lado más humano a través de una técnica impecable en la que predominan los contrastes, los juegos lumínicos y esa atmósfera mística y noctámbula tan propia de los clubs de Jazz.

Unas fotografías que llegarían a empatizar con las necesidades de un público más adulto, que encontraba en el Jazz un modo de esparcimiento sofisticado.

Se trató pues Francis Wolff de un fotógrafo vinculado a las propuestas de diseñadores gráficos con los que realizaba trabajos colaborati-

vos, que obtuvieron como resultado la creación de sobrias y elegantes cubiertas de disco con una sensibilidad que apostaba por la crudeza de un realismo palpable y puro.

Uno de los diseñadores con los que Wolff trabajó fue Paul Bacon, quien en suma se trató del primer diseñador de la compañía. Neoyor- quino y amante del Jazz, Paul comenzó su afición a temprana edad, cuando en 1935 escuchó por primera vez a Benny Goodman en la radio. Pronto iría descubriendo a Artie Shaw, Bix Beiderbecke, Louis Armstrong o Bessie Smith y junto a su hermano formaría parte de un "Hot club" en Newmark; un grupo de adolescentes que se juntaban para escuchar y charlar sobre Jazz, y en el cual Paul Bacon comenzó a desarrollar sus primeras ilustraciones para la revista "Jazz Notes".

Tras ingresar en la marina y formar parte del estudio de diseño Zamboni Associates en Manhattan, Bacon comenzó a realizar sus primeros encargos para Blue Note, entre los que se encontraban covers de Sidney Bechet, Meade Lux Lewis, Edmond Hall, Charlie Christian o Albert Ammons; para los cuales explotó su ingenio gráfico con expresivos dibujos realizados a mano a partir de una limitada paleta reducida a dos tonos.

Paul Bacon, quien posteriormente pasaría a ser director de arte de Riverside Records, se convirtió en una de las piezas fundamentales en el desarrollo de la identidad de Blue Note y fue uno de aquellos ilustradores, anteriormente mencionados, cuya sensibilidad por el Jazz enriquecería su modo de transmitir plásticamente la magia y frescura del género.

Formalmente, vemos como a través de sus más de 200 discos ilustrados, Bacon fue derramando una tenaz personalidad mediante el uso de tipografías e ilustraciones de carácter manual, cuyo dinamismo era capaz de generar movimiento a base de líneas curvas y formas sinuosas irrumpiendo en sus retratos de tipo realista.

Verificamos a través de las propuestas de Blue Note, como en efecto la ilustración supo mantener su hueco en la industria discográfica y compaginarse de un modo magistral con la racionalidad del diseño gráfico o los aportes fotográficos, cada vez más frecuentes en esta conjunción generada a partir de la imagen ilustrada.

Así mismo, Paul Bacon quiso contar para los proyectos de la compañía con su amigo John Hermansader, fundador del "Hot Club" de Newmark al que Bacon perteneció.

Hermansader, quien había estudiado diseño en la New Bauhaus de Chicago, estableció su propia empresa de diseño en Nueva York y trabajó como freelance para la discográfica, tratándose del principal embajador de las pautas de la Bauhaus, lo cual dio lugar a algunos de los más clásicos diseños de los primeros LPs de 10" que el sello comenzó a comercializar en 1951; entre los que podemos encontrar los clásicos de Miles Davis, Jay Jay Johnson o The Amazing Bud Powell, donde progresivamente la fotografía comenzó a cobrar protagonismo, regida por leyes de composición e integración del valor geométrico. [Fig.8] Michael Cuscuna, productor de discos en Blue Note afirmó que

"Lo que John Hermansader y Paul Bacon realmente hicieron fue evocar la sensación de la música. Utilizaron de todo, desde diseños de la Bauhaus hasta recursos que eran realmente de otro mundo...Cuando la gente piensa en Blue Note

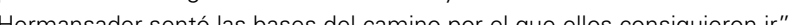


Bibliografía
BACON, Paul; GRAND, Stanley: O'Neal, Hank. The graphic art of Paul Bacon. Wilkes-Barre, Pa: Sordoni Art Gallery, 1999 CHUSID, Irwin; ECONOMON, Barbara. The high fidelity art of Jim Flora. Seattle: Fantagraphics Books, 2013 BHUSID, Irwin and ECONOMON os Jim Flora Seatte: Fantagraphics Books, 2007.

CHUSID, Irwin. The mischievous at os Jim Flora. Seattle: Fantagraphics Books, 2004

COLLINGHAM, Gllynn, CROMEY, Felix and MARSH, Graham. Blue Note, The Album Cover Art. New York: Chronicle Books, 2002 COOK, Richard. Blue Note Record: Charles \& Co, 2003

DIGGS, Frank and LEWINE, Harris (introduction by Paul Bacon). Black Beauty, White Heat, a Pictorial History of Classis Jazz, 1929-1950. FUJITA, Neil. Aim for a Job in Graphic Design/Art. New York: Richards Rosen Press, 1968

H.FALK, Peter, M.LEWIS, Audrey and ROESSLER, Veronika. Who was who in American art, 1564-1975: 400 years of artists in America. Madison, CT: Sound View Press, 1999 York: Praeger Publishers Inc, 1972 PRESCOTT, Kenneth. The Complete Graphic Works of Ben Shahn. New York: Quadrangle, 1973. STEVEN, Heller, STEINWEISS, Alex and REAGAN, Kevin and. Alex Steinweiss. The Inventor of the Modern Album Cover. Taschen, 2011. Catálogo Jazz Gráfico. Diseño y

fotografía en el disco de jazz. 1940-

Recursos web

www.alexsteinweiss.com

www.allaboutjazz.com

www.birkajazz.com

www.bluenote.net

www.columbiarecords.com

www.dazeddigital.com

www.designishistory.com

www.eyemagazine.com

www.jazzwax.com

www.jimflora.com

www.lpcoverlover.com

www.miltonglaser.com

www.vinylrevival.com
www.visual.gi
Al finalizar Hermansader su carrera con Blue Note, fue contratado en la compañía Reid Miles, quien se encargaría de desarrollar los diseños de las primeras grabaciones en 12 ".

Sus propuestas lograron revolucionar de nuevo el arte plástico del Jazz y convertirse en icónicas obras del diseño gráfico aplicado al disco.

Cabe señalar que la ilustración quedó presente en numerosos de sus diseños, para los cuales apostó por artistas como Phil Hays, Paula Donohue o un joven Andy Warhol, de retratos lineales y espontáneos trazos a tinta.

Resultando sin embargo ser los más populares, los fotomontajes

que realizó a partir de las fotografías de su compañero Francis Wolff,

con el que se complementó técnicamente y desarrolló gran parte de sus obras; incluyendo más adelante sus propias fotografías, hasta finalmente obviar las mismas y trabajar con tintas planas, color y formas tipográficas, a partir de una interesante disposición de elementos.

De nuevo podemos comprobar un camino hacia la abstracción que siguiendo el rumbo marcado por las tendencias artísticas quedaba reflejado en la gráfica del disco.

Un legado de diseños de elegancia vanguardista que convirtieron a

Miles en un artista infinitamente evocador e innovador, representativo de un tipo de arte más cercano a la abstracción, donde también podríamos ubicar las rotundas pinturas de Martin Craig, o las propuestas Gil Mellé, otro de los artistas que formó parte del revolucionario equipo de Blue Records.

Gil Mellé, fue un alma libre, tocaba el saxo y exponía sus pinturas y esculturas en la ciudad de Nueva York, cuando conoció a Alfred Lion con quien realizó varias grabaciones en su discográfica Blue Note, donde pronto también comenzaría a trabajar como diseñador gráfico.

El arte experimental de Mellé, quien posteriormente continuaría su carrera en Prestige Records, quedó reflejado en numerosos discos de colores vibrantes, donde combinaba fotografía, ilustración y tipografía con una personalidad tan espontánea e irracional como la del propio Jazz.

\section{Conclusiones}

Para finalizar, cabe realizar una recopilación de datos con los que hemos podido vislumbrar ciertas hipótesis que hemos ido planteando a lo largo de la investigación; una serie de conclusiones que nos es posible extraer a partir de un análisis de tipo documental que nos ha servido para contextualizar la incorporación de la imagen ilustrada al disco.

Primeramente, comprobamos cómo en efecto la idea de Alex Steinweiss dio lugar a un nuevo formato comunicativo para ilustradores y creadores plásticos que encontraron en la cubierta del disco un espacio donde poder generar piezas de arte, que sirvieran de premisa a las grabaciones en el producto contenidas.

Unos géneros musicales igualmente novedosos e inspiradores para unos artistas que encontrarían en el Jazz una serie de valores basados en la espontaneidad y el juego creativo, que conceptual y gráficamente veríamos reflejados en aquellos diseños que no tardaron en contar con un packaging propio acorde a sus necesidades de carácter técnico y moral. $\overline{\text { Claudia Torán }}$

Actualmente cursa los estudios de Doctorado, es licenciada en Bellas Máster de Diseño en a traves del la Universidad Politécnica de Valen cia. Ejerce como Comisaria artística en Espacio Inestable (Valencia) y se propone dedicar su carrera a la ilustración y la investigación de la misma en el terreno musica
Afrontamos de qué modo la imagen aplicada al álbum contó con importantes repercusiones sociales, ya que no únicamente supuso un aumento desproporcionado en los balances de ventas, sino que en suma trajo consigo una nueva concepción y percepción de la música. Una nueva forma de ver, vender y entender la música; la cual por vez primera, estaba siendo filtrada por la creación gráfica, quedando el contenedor de la misma en manos de artistas exponentes de las últimas tendencias.

Una idea revolucionaria, fruto de la labor del ilustrador comercial y el diseñador gráfico, cuyo cometido siempre se ha basado en examinar las necesidades del consumidor con el objeto de lograr un producto atractivo, innovador y consecuentemente eficaz.

Comprobamos cómo el diseño del disco supuso pues un giro perceptivo en el terreno sociológico, patente en la veloz aceptación y popularidad generada por el objeto en cuestión, que de nuevo nos lleva a plantearnos la importancia del valor estético; un enfoque casi platónico que otorga valor al goce como fin último del espectador frente a la obra.

$Y$ es que, en relación a la propia estética del producto, hemos podido analizar cómo las influencias de los artistas plásticos implicados en tales diseños, han sido fruto de unas fuentes referenciales similares, basadas en el arte europeo y las características definitorias de las Vanguardias, así como la cartelería de los años 30, el Art Deco o los valores compositivos de la escuela de la Bauhaus. Influencias perceptibles que bien lograrían generar un amplio abanico de posibilidades gráficas, debido también a la libertad creativa aceptada en los encargos, la cual dio lugar a una libre expresión, donde tanto la pintura como la fotografía o la tipografía supieron convivir con la imagen ilustrada; complementándose entre sí en propuestas transgresoras a nivel compositivo y comercial que lograron convertirse en auténticas obras de arte, con posterior repercusión en el terreno de la ilustración aplicada a producto y el diseño gráfico.

Una calidad artística que serviría como aliciente al producto en un periodo en el que el arte se encontraba en plena efervescencia transformadora y rupturista, en la cual la abstracción se abría paso en una población de entre guerras y cambios culturales que marcarían el inicio de una sociedad moderna.

Así mismo, hemos podido comprobar de qué modo la transformación y el desarrollo cultural, presente en el desarrollo de nuevos géneros musicales como el Rocanrol, supusieron un cambio de valores y una transformación metodológica, donde la fotografía comenzó a cobrar protagonismo. Una transformación de valores a la cual los ilustradores supieron responder y adaptarse, a base de una mayor experimentación técnica.

Entendemos pues el inicio del cover ilustrado como el nacimiento de un nuevo medio para la creación artística; una etapa que supuso una influyente revolución plástica no únicamente en el terreno de la música y el diseño gráfico sino también en la propia Historia de la ilustración. 